\section{(2) OPEN ACCESS}

\title{
Persistent symptoms 1.5-6 months after COVID-19 in non-hospitalised subjects: a population-based cohort study
}

\author{
Knut Stavem ำ , 1,2,3 Waleed Ghanima, 4,5 Magnus Kringstad Olsen, ${ }^{6}$ \\ Hanne Margrethe Gilboe, ${ }^{7}$ Gunnar Einvik ${ }^{1,3}$
}

\begin{abstract}
- Additional material is
published online only. To view, please visit the journal online (http://dx.doi.org/10.1136/ thoraxjnl-2020-216377).
\end{abstract}

'Department of Pulmonary Medicine, Akershus University Hospital, Lørenskog, Norway ${ }^{2}$ Health Services Research Unit, Akershus University Hospital, Lørenskog, Norway

${ }^{3}$ Institute of Clinical Medicine, Campus Ahus, Faculty of Medicine, University of Oslo, Lørenskog, Norway

${ }^{4}$ Haematology and Oncology, Sykehuset Østfold HF, Grålum, Norway

${ }^{5}$ Institute of Clinical Medicine, University of Oslo, Oslo, Norway ${ }^{6}$ Department of Research, Sykehuset Østfold HF, Grålum, Norway

${ }^{7}$ Medical Microbiology, Fürst Medisinsk Laboratorium, Oslo, Norway

\section{Correspondence to}

Professor Knut Stavem, Department of Pulmonary Medicine, Akershus University Hospital, Lørenskog 1478, Norway;

knut.stavem@medisin.uio.no

Received 12 October 2020 Revised 13 November 2020 Accepted 16 November 2020 Published Online First 3 December 2020

\section{Linked}

- http://dx.doi.org/10.1136/ thoraxjnl-2020-216226

\section{Check for updates}

(C) Author(s) (or their employer(s)) 2021. Re-use permitted under CC BY-NC. No commercial re-use. See rights and permissions. Published by BMJ.

To cite: Stavem $\mathrm{K}$ Ghanima W, Olsen MK, et al. Thorax 2021;76:405-407.

\section{ABSTRACT}

This study assessed symptoms and their determinants 1.5-6 months after symptom onset in non-hospitalised subjects with confirmed COVID-19 until 1 June 2020, in a geographically defined area. We invited 938 subjects; $451(48 \%)$ responded. They reported less symptoms after 1.5-6 months than during COVID-19; median (IQR) 0 $(0-2)$ versus $8(6-11)$, respectively $(p<0.001) ; 53 \%$ of women and $67 \%$ of men were symptom free, while $16 \%$ reported dyspnoea, $12 \%$ loss/disturbance of smell, and $10 \%$ loss/disturbance of taste. In multivariable analysis, having persistent symptoms was associated with the number of comorbidities and number of symptoms during the acute COVID-19 phase.

\section{INTRODUCTION}

Symptoms and disease severity of COVID-19 vary from asymptomatic to severe or fatal illness, with up to $15 \%$ requiring hospital admission. ${ }^{1}$ Most of the available follow-up data on COVID-19 involve hospitalised patients. ${ }^{2-4}$ Fatigue and dyspnoea are common about 60 days after the onset of COVIDrelated symptoms in previously hospitalised patients with COVID-19. ${ }^{2}$ Limited data are available on the course of COVID-19 symptoms in nonhospitalised patients, who constitute the majority of patients. ${ }^{5}$ This study assessed symptoms and determinants of symptoms in a population-based cohort of non-hospitalised subjects 1.5-6 months after COVID-19.

\section{METHODS}

\section{Participants and survey}

This was a cross-sectional mixed-mode survey of a geographical cohort in the catchment areas of two Norwegian hospitals (Akershus University Hospital (Ahus), Østfold Hospital (ØH)), comprising 900000 inhabitants, or $17 \%$ of the Norwegian population.

We identified all PCR SARS-CoV-2-positive subjects $\geq 18$ years from the microbiology laboratories of the two hospitals and the largest private microbiology laboratory in the area, Fürst Medical Laboratory, until 1 June 2020. We anticipate that these labs will have analysed an overwhelming majority of the COVID-19 tests in the area. Patients were eligible if they had not been hospitalised for COVID-19. We assumed that if a patient was hospitalised within 3 weeks of a positive PCR test for SARS-CoV-2, there was a high probability that this was COVID-19-related. Therefore, we excluded those with a hospital admission $<22$ days after a positive PCR test. Of 1029 eligible subjects, we excluded 89 (27 no Norwegian identification number, 56 residing outside area, 6 other); hence, we invited 938 subjects to participate in the survey (online supplemental figure 1).

A postal survey in the end of June 2020 provided study information and a consent form to eligible subjects, about 1-4 months after the positive PCR test. The invited subjects could respond on paper or electronically. In early August, we sent one postal reminder to non-respondents.

Comorbidity was recorded using a checklist of 21 diseases and conditions, 18 of which constituted a self-report version of the Charlson comorbidity index. ${ }^{6}$ We totalled the number of comorbidities and categorised this as $0,1, \geq 2$ comorbidities.

Symptoms during the acute phase of COVID-19 and at the time of survey were assessed using a checklist of 23 self-reported symptoms, largely adopted from the WHO/ISARIC platform. ${ }^{7}$ We quantified the severity of the acute COVID-19 phase using the number of these retrospectively reported symptoms, categorised into tertiles (0-5, $6-9,10-23)$.

\section{Statistical analysis}

We compared descriptive variables for respondents and non-respondents using the t-test or $\chi^{2}$ test, as appropriate. Symptom scores during COVID-19 and at the time of the survey were compared using Wilcoxon's matched-pairs test.

Determinants of symptoms were analysed using multivariable negative binomial regression analysis with the number of symptoms (out of 23) at the time of the survey as the dependent variable, reporting the incidence rate ratio (IRR) for one more symptom. As independent variables, we included: age (per decade), sex, education (three levels), marital status (three categories), smoking status (never smoker, ex-smoker/current smoker), body mass index (BMI) $\left(\mathrm{kg} / \mathrm{m}^{2}\right)$, categories of number of 21 self-reported comorbidities $(0,1,2$, $\geq 3$ ), tertiles of number of symptoms during the acute COVID-19 (0-5, 6-9, 10-23), and tertiles of time from onset of symptoms to response (41-110, 11-127, 128-193 days). All variables were forced into the model.

We chose a 5\% significance level. 


\begin{tabular}{|c|c|}
\hline Age (years), mean (SD) & $49.8(15.2)$ \\
\hline Sex, female & $253(56)$ \\
\hline \multicolumn{2}{|l|}{ Marital status } \\
\hline Single/divorced/separated & $99(22)$ \\
\hline Married/cohabiting & $332(74)$ \\
\hline Widowed & $19(4)$ \\
\hline Born in Norway ( $n=447$ ) & 376 (84) \\
\hline Norwegian mother tongue $(n=448)$ & $375(84)$ \\
\hline Both parents born in Norway $(n=450)$ & $350(78)$ \\
\hline \multicolumn{2}{|l|}{ Highest attained education } \\
\hline Primary school & $41(9)$ \\
\hline Secondary school & $170(38)$ \\
\hline University & $240(53)$ \\
\hline \multicolumn{2}{|l|}{ Smoking status ( $n=446$ ) } \\
\hline Never smoker & $292(65)$ \\
\hline Ex-smoker & $128(29)$ \\
\hline Current smoker & $26(6)$ \\
\hline Body mass index $\left(\mathrm{kg} / \mathrm{m}^{2}\right)(\mathrm{n}=444)$ & $26.8(5.2)$ \\
\hline Influenza vaccination second half of $2019(\mathrm{n}=449)$ & $140(31)$ \\
\hline \multicolumn{2}{|l|}{ No. of 21 comorbidities } \\
\hline 0 & $228(51)$ \\
\hline 1 & $128(28)$ \\
\hline 2 or more & $95(21)$ \\
\hline \multicolumn{2}{|l|}{ Place of contraction } \\
\hline Norway, known contact & $191(42)$ \\
\hline Norway, unknown contact & $142(32)$ \\
\hline Travel abroad & $115(16)$ \\
\hline
\end{tabular}

Number (\%), unless specified otherwise.

\section{RESULTS}

In total, 451 subjects (48 \%) responded to the survey, of whom $221(49 \%)$ responded to the web version. The respondents and non-respondents had a mean ages (as of 1 June 2020) of 49.7 (SD 15.2) and $43.8(17.3)$ years $(\mathrm{p}<0.001)$, while 253 (56 $\%)$ and $222(46 \%)$, respectively, were women $(p=0.001)$. The response rates in seven aggregated geographical districts within the catchment areas of the hospitals ranged from $26 \%(27 / 112$, Oslo) to $65 \%$ (110/169, Follo). Respondents' characteristics are shown in table 1 . The three most common comorbidities were hypertension 86 (19\%), arthrosis 57 (13\%) and asthma 52 $(12 \%)$.

The time from symptom onset until the survey was median 117 days (range 41-193) ( $n=445)$. The most prevalent symptoms during COVID-19 and at the time of the survey are shown in figure 1.

In total, 133 women (53\%) and 133 men (67\%) reported no current symptoms (online supplemental figure 2). The number of symptoms per subject declined from the acute COVID-19 to follow-up, median (IQR) $8(6-11)$ and $0(0-2)$, respectively $(\mathrm{p}<0.001)$.

The symptom load during the acute COVID-19 phase and number of comorbidities were associated with the number of symptoms at follow-up (table 2). There was no association of the other independent variables with symptom load at follow-up.

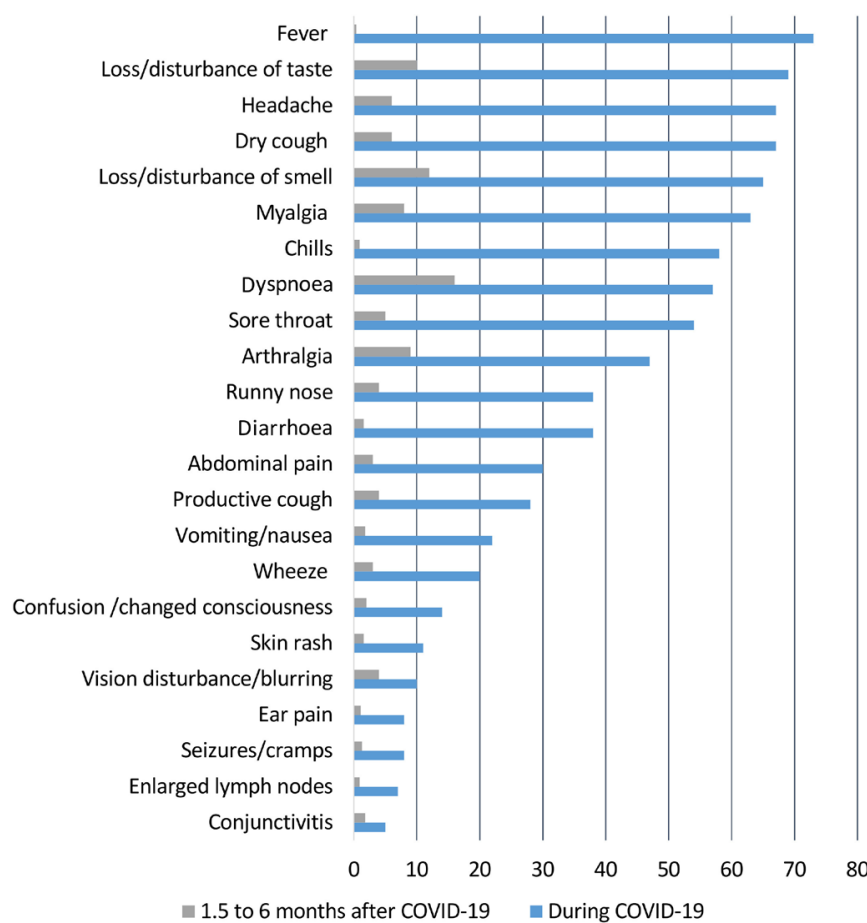

Figure 1 Symptoms during COVID-19 and 1.5-6 months later, in per cent.

\section{DISCUSSION}

This study found a reduction in symptoms from the acute COVID-19 episode to the time of the survey, and $>50 \%$ of nonhospitalised COVID-19 subjects had no symptoms 1.5-6 months after symptom onset. Comorbidities and a high symptom load during the acute phase were associated with persistent symptoms. At 1.5-6 months, however, there was no difference in symptoms according to length of time since COVID-19 onset.

Few similar studies of non-hospitalised patients exist for comparison. The proportion of symptom-free patients in the present survey was much larger than among non-hospitalised subjects with COVID-19 recruited from Facebook groups and a panel expressing interest in COVID-19, which comprised 91\% women. ${ }^{8}$ The proportion reporting persistent symptoms in this study was lower than that reported 45-60 days after hospitalisation for COVID-19. ${ }^{2}$

The association of persistent symptoms with comorbidities and symptom load during the acute phase of COVID-19 support previous findings, ${ }^{8}$ though in the present study there was no association with age. The length of the time between the acute phase and the survey was not associated with the symptom load, which suggests that the improvement in symptoms primarily occurred during the first few weeks after the acute phase. This was a crosssectional analysis and should therefore be interpreted cautiously.

Limitations of this study are that we did not assess fatigue or mental health symptoms with similar single items, or symptom severity at maximum or follow-up, or homogeneous ethnicity, which may be associated with health. The responses in our study were biased towards women and subjects $>50$ years of age, and the response rate was low in three boroughs of Oslo with a high proportion of immigrants. Moreover, the items on symptoms during COVID-19 were retrospective and may be subject to recall bias.

Protracted symptoms following infectious diseases are not unique for COVID-19, but are common in many viral and bacterial infections and may last for several months. ${ }^{9}{ }^{10}$ Longitudinal studies with longer follow-up are warranted to assess the course of persistent symptoms following COVID-19. 
Table 2 Determinants of number of symptoms at follow-up multivariable negative binomial regression analysis $(n=434)$

\begin{tabular}{lcllc}
\hline & N & $\begin{array}{l}\text { Incidence } \\
\text { rate ratio }\end{array}$ & $95 \% \mathrm{Cl}$ & P value \\
\hline Age & 434 & 0.94 & 0.82 to 1.07 & 0.36 \\
\hline Sex & & & & \\
\hline Femalet & 243 & 1 & & \\
\hline Male & 191 & 0.74 & 0.53 to 1.03 & 0.072 \\
\hline Marital status & & & & \\
\hline Single/separated/divorcedt & 92 & 1 & & \\
\hline Married/cohabiting & 325 & 0.89 & 0.60 to 1.31 & 0.55 \\
\hline Widowed & 17 & 0.56 & 0.22 to 1.46 & 0.24 \\
\hline Highest attained education & & & & \\
\hline$<11$ years (Compulsory school) $\dagger$ & 37 & 1 & & \\
\hline 11-13 years (Secondary school) & 162 & 0.87 & 0.49 to 1.54 & 0.62 \\
\hline$>13$ years (University) & 235 & 0.83 & 0.47 to 1.46 & 0.52 \\
\hline Smoking status & & & & \\
\hline Never smokert & 286 & 1 & & \\
\hline Former/current smoker & 148 & 1.16 & 0.83 to 1.62 & 0.40 \\
\hline
\end{tabular}

No. of 21 comorbidites

$\begin{array}{lrrrr}0+ & 218 & 1 & & \\ 1 & 122 & 1.52 & 1.02 \text { to } 2.25 & 0.038 \\ \geq 2 & 94 & 2.52 & 1.58 \text { to } 4.02 & <0.001\end{array}$

No. of 23 COVID-19 symptoms

\begin{tabular}{|cccccc|}
\hline $0-5 \dagger$ & 99 & 1 & & \\
\hline $6-9$ & 167 & 1.97 & 1.20 to 3.23 & 0.007 \\
\hline $10-23$ & 168 & 4.16 & 2.57 to 6.72 & $<0.001$ \\
\hline Body mass index, $\mathrm{kg} / \mathrm{m}^{2}$ & 434 & 0.99 & 0.97 to 1.02 & 0.63 \\
\hline Time from onset of symptoms, days & & & & \\
\hline $41-110$ & 143 & 1.27 & 0.86 to 1.87 & 0.24 \\
\hline $111-127$ & 152 & 1.26 & 0.85 to 1.86 & 0.25 \\
\hline $128-193^{*}$ & 139 & 1 & & \\
\hline
\end{tabular}

*Per decade.

tReference category.

In conclusion, this study has shown that persistent symptoms were common after COVID-19 in non-hospitalised patients and were related to the symptom load and number of comorbidities present during the acute phase, but the majority of patients were symptom-free 1.5 to 6 months after COVID-19 onset.

Contributors KS initiated the study, participated in study planning, designed data collection tools and questionnaire, monitored data collection, prepared the statistical analysis plan, cleaned and analysed the data, and drafted and revised the paper
He is guarantor. WG contributed in study planning, administered and monitored data collection, and revised the paper. MKO participated in study planning, data collection, analysis and in revising the paper. HMG participated in planning the study, data collection and in revising the paper. GE contributed in study conception, study planning, data collection and monitoring, analysis and revised the paper. All authors reviewed and approved the final version.

Funding This study was supported by internal funds in the participating institutions. The study team had full control over all aspects of the study design, analysis, and write-up.

Competing interests All authors have completed the ICMJE uniform disclosure form at www.icmje.org/coi_disclosure.pdf. WG reports grants and personal fees from Novartis, grants and personal fees from Amgen, grants from Bayer, grants from BMS, grants from Pfizer, personal fees from MSD, outside the submitted work. The other authors declare: no support from any organisation for the submitted work: no financial relationships with any organisations that might have an interest in the submitted work in the previous three years; no other relationships or activities that could appear to have influenced the submitted work.

\section{Patient consent for publication Not required.}

Ethics approval The Regional Committees for Medical and Health Research Ethics, Health Region South East (approval no. 2020/149384) and the Data Protection Officer at Akershus University Hospital approved the study.

Provenance and peer review Not commissioned; externally peer reviewed.

Open access This is an open access article distributed in accordance with the Creative Commons Attribution Non Commercial (CC BY-NC 4.0) license, which permits others to distribute, remix, adapt, build upon this work non-commercially, and license their derivative works on different terms, provided the original work is properly cited, appropriate credit is given, any changes made indicated, and the use is non-commercial. See: http://creativecommons.org/licenses/by-nc/4.0/.

\section{ORCID iD}

Knut Stavem http://orcid.org/0000-0003-4512-8000

\section{REFERENCES}

1 Guan W-J, Ni Z-Y, Hu Y, et al. Clinical characteristics of coronavirus disease 2019 in China. N Engl J Med 2020;382:1708-20.

2 Carfi A, Bernabei R, Landi F, et al. Persistent symptoms in patients after acute COVID-19. JAMA 2020;324:603-5

3 Moradian ST, Parandeh A, Khalili R, et al. Delayed symptoms in patients recovered from COVID-19.

4 Halpin SJ, Mclvor C, Whyatt G, et al. Postdischarge symptoms and rehabilitation needs in survivors of COVID-19 infection: a cross-sectional evaluation. J Med Virol 2020 doi:10.1002/jmv.26368. [Epub ahead of print: 30 Jul 2020].

5 Burke RM, Killerby ME, Newton S, et al. Symptom Profiles of a Convenience Sample of Patients with COVID-19 - United States, January-April 2020. MMWR Morb Mortal Wkly Rep 2020;69:904-8.

6 Katz JN, Chang LC, Sangha 0, et al. Can comorbidity be measured by questionnaire rather than medical record review? Med Care 1996;34:73-84.

7 WHO/ISARIC. COVID-19 case record form. Global COVID-19 clinical platform novel coronavirus (COVID-19) -rapid version. Available: https://media.tghn.org/medialibrary/ 2020/09/ISARIC_COVID-19_RAPID_CRF_25Aug20.pdf

8 Goërtz YMJ, Van Herck M, Delbressine JM, et al. Persistent symptoms 3 months after a SARS-CoV-2 infection: the post-COVID-19 syndrome? ERJ Open Research 2020:542-2020.

9 Lam MH-B, Wing Y-K, Yu MW-M, et al. Mental morbidities and chronic fatigue in severe acute respiratory syndrome survivors: long-term follow-up. Arch Intern Med 2009:169:2142-7

10 Metlay JP, Fine MJ, Schulz R, et al. Measuring symptomatic and functional recovery in patients with community-acquired pneumonia. J Gen Intern Med $1997 ; 12: 423-30$. 